\title{
ENRAIZAMENTO DE ESTACAS HERBÁCEAS DE 'Mirabolano' (Prunus cerasifera Ehrn) EM DIFERENTES SUBSTRATOS E CONCENTRAÇÕES DE ÁCIDO INDOLBUTÍRICO ${ }^{1}$
}

\author{
JOSÉ DARLAN RAMOS ${ }^{7}$, LUIZ EUGÊNIO SANTOS MATOS ${ }^{6}$, TIAGO CHALTEIN ALMEIDA GONTIJO², RAFAEL PIO ${ }^{5}$, \\ KEIZE PEREIRA JUNQUEIRA ${ }^{3}$, FLÁVIA CARVALHO SANTOS ${ }^{4}$
}

\begin{abstract}
RESUMO - O presente trabalho foi realizado com o objetivo de testar diferentes dosagens de AIB (ácido indolbutírico) e diferentes substratos no enraizamento de estacas herbáceas do porta-enxerto de ameixeira 'Mirabolano'. As estacas foram retiradas de plantas localizadas no município de Wenceslau Bráz-MG, sendo transportadas em câmara fria para a Fazenda Experimental da Epamig, localizada em Maria da Fé-MG, onde foram padronizadas com um par de meias-folhas e $12 \mathrm{~cm}$ de comprimento, sendo posteriormente imersas por 5 segundos em soluções contendo diferentes dosagens de AIB (0; 1000; 2000 e 4000 mg. $\left.\mathrm{L}^{-1}\right)$. Em seguida, foram levadas até bancadas contendo diferentes substratos (areia esterelizada e vermiculita), em local com 50\% de sombreamento e umidade controlada, permanecendo sob estas condições por 60 dias. As variáveis analisadas foram: porcentagem de enraizamento, número de raízes, comprimento médio das raízes e biomassa seca das raízes. Observou-se maior eficiência da vermiculita na obtenção de estacas com maior comprimento médio das raízes e maior porcentagem de enraizamento. Quanto às demais variáveis, não houve diferença significativa entre o uso dos substratos em questão. Com relação à dosagem de AIB, a concentração de $2000 \mathrm{mg}$. $\mathrm{L}^{-1} \mathrm{mostrou}$-se superior às demais para todas as variáveis analisadas.
\end{abstract}

Termos para indexação: Prunus; AIB; propagação; porta-enxerto.

\section{ROOTING OF HERBACEOUS CUTTINGS OF 'MIRABOLANO' (Prunus cerasifera Ehrn) USING DIFFERENT SUBSTRATES AND CONCENTRATIONS OF INDOL BUTIRIC ACID}

\begin{abstract}
An experiment was conducted in order to verify different concentrations of IBA (indol butiric acid) and different substrates in the rooting of herbaceous cuttings of the rootstock 'Mirabolano'. The cuttings were obtained from plants at Wenceslaw Bráz-MG and taken, under low temperature, to the EPAMIG's Experimental Farm in Maria da Fé-MG. The cuttings were standardized with one pair of leaves, cutted on half and $12 \mathrm{~cm}$ of lengh, treated with different concentrations of IBA $\left(0,1000,2000\right.$ and $\left.4000 \mathrm{mg} . \mathrm{L}^{-1}\right)$ and taken to wark-benchs filled with different substrates (sterilized sand and vermiculite), under shadow (50\%) and humidity control. After 60 days, the rooting percentage, number of leaves, roots average size and roots dry matter were evaluated. The vermiculite permitted the obtaining of cuttings with larger average length of roots and higher rooting percentage. For other characteristics, there was not difference between the results usings sand or vermiculite. The concentration of $2000 \mathrm{mg} . \mathrm{L}^{-1}$ of IBA promoted better results then the others, for all the evaluated characteristics.
\end{abstract}

Index terms: Prunus; IBA; propagation; rootstocks.

As ameixeiras (Prunus sp.) são frutíferas de clima temperado, não suportam frio excessivo e toleram bem as temperaturas elevadas, desenvolvendo-se satisfatoriamente em quase todas as regiões do País. Possui ampla adaptação no Sul do Estado de Minas Gerais, onde se concentra a maior produtividade do País (20 t/ha), com uma produção aproximada de 1600 ton, com área plantada de 80 ha (Brasil, 2000).

A propagação desta espécie é realizada por enxertia, sendo o 'Mirabolano' (Prunus cerasifera Ehrn) uma excelente alternativa como porta-enxerto devido a sua rusticidade. Ao utilizar sementes para a obtenção dos porta-enxertos, estes podem não transmitir as mesmas características genéticas da planta-mãe. A utilização de sementes de ameixeira para obtenção de porta-enxertos é inviável, devido ao seu baixo índice de germinação. Assim, o processo de estaquia, como método de propagação da ameixeira para produção de porta-enxertos, é uma alternativa que está sendo pesquisada no Brasil e em outras partes do mundo (Dutra et al., 1998).

A dificuldade de enraizamento das estacas envolvendo a participação tanto de fatores relacionados à própria planta, como também ao ambiente, constitui-se um dos mais sérios problemas, sendo importante a busca de técnicas auxiliares, como o uso de reguladores de crescimento, para assim proporcionar uma melhoria do enraizamento (Biasi, 1996; Mayer, 2001; PIO, 2002).

O grupo de reguladores de crescimento usado com maior freqüência é o das auxinas, que são essenciais no processo de enraizamento, possivelmente por estimularem a síntese de etileno, favo- recendo assim a emissão de raízes (Norberto et al., 2001), para que haja um balanço hormonal endógeno adequado, especialmente entre auxinas, giberelinas e citocininas, equilibrando os promotores e inibidores no processo de iniciação radicular. A maneira mais comum de promover esse equilíbrio é pela aplicação exógena de reguladores de crescimento, como AIB (ácido indolbutírico), que podem elevar o teor de auxina no tecido (Pasqual et al., 2001).

Outra questão importante no processo de estaquia é a utilização do substrato (Peixoto, 1986). Os melhores substratos devem apresentar, entre outras importantes características, ausência de patógeno, riqueza em nutrientes essenciais, textura e estrutura adequadas (Silva et al., 2001). Hoffmann et al. (1996) afirmam que o substrato é um dos fatores de maior importância no enraizamento de estacas. O substrato ideal para o enraizamento de estacas deve ser poroso, sendo uma excelente alternativa o uso de areia ou vermiculita (Oliveira, 2000).

Sendo assim, o presente trabalho foi realizado com o objetivo de testar diferentes concentrações de AIB (ácido indolbutírico) e verificar o efeito de diferentes substratos no enraizamento de estacas herbáceas do porta-enxerto 'Mirabolano'.

O presente trabalho foi desenvolvido na Fazenda Experimental da Epamig, localizada em Maria da Fé-MG, no período de novembro de 2001 a janeiro de 2002.

As estacas foram retiradas de uma coleção de plantas adultas sadias, de aproximadamente 4 anos de idade, localizadas no município de Wenceslau Bráz-MG, sendo padronizadas com um par de meias-fo-

\footnotetext{
1 (Trabalho 108/2002). Recebido: 25/07/2002; Aceito para publicação: 19/03/2003

2 Graduando do curso de Agronomia, Bolsista de Iniciação Científica-CNPq, Universidade Federal de Lavras/UFLA. tiagocgontijo@bol.com.br

${ }^{3}$ Graduando do curso de Agronomia, Bolsista de Iniciação Científica-CNPq, Universidade Federal de Lavras/UFLA. keize.junqueira@bol.com.br

${ }^{4}$ Graduando do curso de Agronomia, Bolsista de Iniciação Científica-CNPq, Universidade Federal de Lavras/UFLA. flavinhaom@uol.com.br

${ }^{5}$ Eng $^{\circ}$. Agrônomo, M.Sc., Doutorando do curso de Fitotecnia, Universidade de São Paulo, Escola Superior de Agricultura “Luiz de Queiroz" - ESALQ/USP. Rua Nove, n.168 - Iate Clube de Americana, CEP 13465-000, Americana-SP. Autor para correspondência. rafapio@esalq.usp.br

${ }^{6}$ Eng. Agrônomo, Pesquisador EPAMIG - Fazenda Experimental de Maria da Fé-MG/FEMF.

${ }^{7}$ Eng. Agrônomo, Dr., Prof. Adjunto IV do Depto. de Agricultura, Universidade Federal de Lavras/UFLA, C.P. 37, CEP 37200-000, Lavras-MG. darlan@ufla.br
} 
lhas e $12 \mathrm{~cm}$ de comprimento, tendo suas bases imersas em solução líquida de AIB $\left(0 ; 1000 ; 2000\right.$ e 4000 mg. $\left.\mathrm{L}^{-1}\right)$ por 5 segundos, para só então serem levadas até bancadas contendo diferentes substratos (areia esterelizada e vermiculita), em local com $50 \%$ de sombreamento e umidade controlada. $O$ delineamento foi o inteiramente casualizado, em arranjo fatorial de 4 X 2, com 5 repetições e 10 estacas por parcela.

As avaliações dos tratamentos foram realizadas 60 dias após a instalação do ensaio, através de coleta dos seguintes dados biométricos: porcentagem de enraizamento, número de raízes, comprimento médio das raízes e biomassa seca das raízes. Os dados experimentais foram submetidos à análise de variância, as médias ao teste Tukey e os níveis de AIB à regressão, ao nível de 0,05 de probabilidade, sendo seguidas as recomendações de Gomes (2000).

Através da interpretação dos dados da análise de variância, constatou-se que houve efeito significativo na interação entre os níveis de ácido indolbutírico (AIB) e os tipos de substratos em estudo, apenas para a variável porcentagem de estacas enraizadas; porém, houve diferença significativa entre os níveis de AIB para as demais variáveis analisadas. De acordo com o teste Tukey, observou-se que houve diferença significativa entre os tipos de substratos apenas para a variável comprimento médio das raízes.

O maior comprimento médio das raízes foi adquirido com a utilização do substrato vermiculita, obtendo-se comprimento médio das raízes na ordem de $1,97 \mathrm{~cm}$, enquanto a areia proporcionou apenas 1,07 $\mathrm{cm}$. Segundo Pasqual et al. (2001), a vermiculita possui alta capacidade de retenção de água (400-500 $\mathrm{cm}^{3}$ de água $/ \mathrm{dm}^{3}$ de substrato). Tal fato pode ter uma relação direta com a superioridade demonstrada pela vermiculita, quando comparada à areia esterelizada, na obtenção de estacas com maior comprimento médio de raízes.

Observando a Figura 1, verifica-se que o substrato vermiculita proporcionou maior porcentagem de estacas enraizadas comparado à areia esterelizada, perfazendo um total de $37 \%$ e $10 \%$ de estacas enraizadas, respectivamente, ambos na presença de $2000 \mathrm{mg} . \mathrm{L}^{-1}$ de AIB. O tipo de substrato é um dos fatores de maior influência no enraizamento de estacas, especialmente no caso de espécies de difícil enraizamento (Fachinello et al., 1995). Segundo Hartmann et al. (1997), a vermiculita destaca-se entre os demais substratos no enraizamento de estacas devido à porosidade e retenção de água que a caracterizam. O efeito do AIB no enraizamento de estaca também foi demonstrado por Dutra et al. (1998), quando mencionaram que a aplicação da solução de auxina AIB aumentou a porcentagem de estacas enraizadas de ameixeira das cultivares Roxa de Itaquera (34,45\%), Songold (19,96\%) e Beauty $(22,67 \%)$.

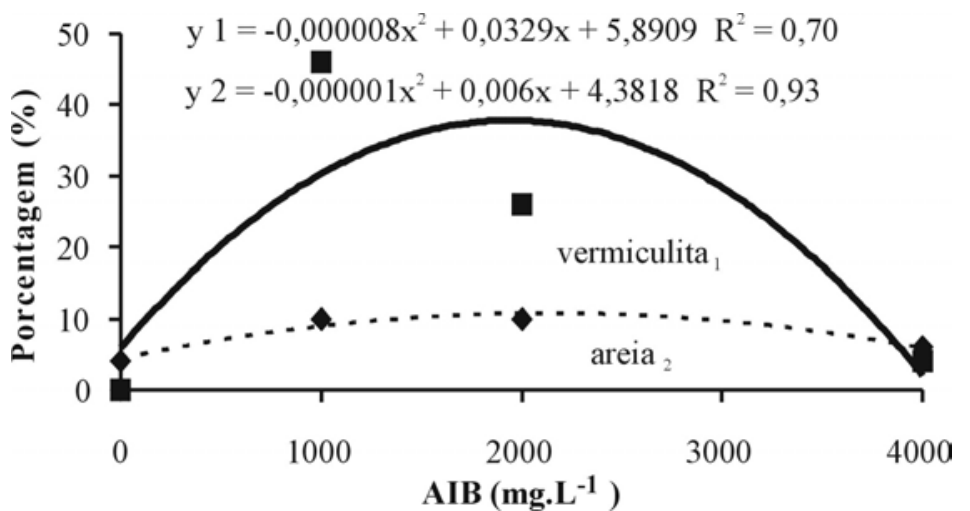

FIGURA 1- Porcentagem de estacas enraizadas do porta-enxerto de ameixeira 'Mirabolano'. Lavras-MG, UFLA, 2002.

De acordo com as Figuras 2, 3 e 4, observa-se que a concentração de $2000 \mathrm{mg} . \mathrm{L}^{-1}$ do regulador de crescimento AIB promoveu os melhores resultados, obtendo-se aproximadamente 7 raízes por estaca, raízes com 2,5 cm de comprimento médio e 7,21 $\mathrm{mg}$ de biomassa seca das raízes, respectivamente. Observando-se ainda as Figuras mencionadas, verifica-se que, conforme houve o aumento das concentrações de AIB aplicadas na base das estacas, ocorreu um acréscimo nos resultados destas respectivas variáveis, chegando a um ponto onde começou a haver um decréscimo. Este comportamento pode estar relacionado com o fato de as estacas possuírem uma certa quantidade endógena de hormônios, promotores ou inibidores, de enraizamento. $\mathrm{O}$ fornecimento exógeno de auxina, em certas quantidades, pode promover uma alteração hormonal, favorecendo ou não o enraizamento.

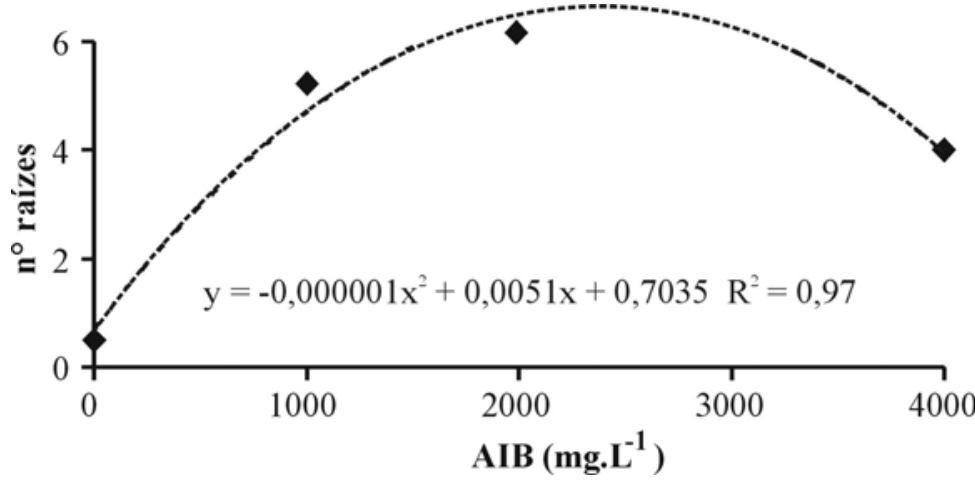

FIGURA 2 - Número de raízes do porta-enxerto de ameixeira 'Mirabolano'. Lavras-MG, UFLA, 2002.

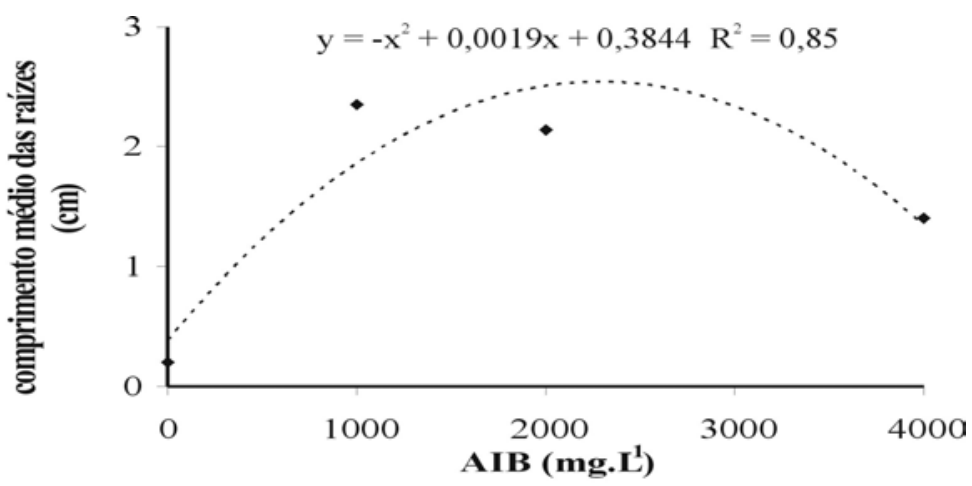

FIGURA 3- Comprimento médio das raízes do porta-enxerto de ameixeira 'Mirabolano'. Lavras-MG, UFLA, 2002.

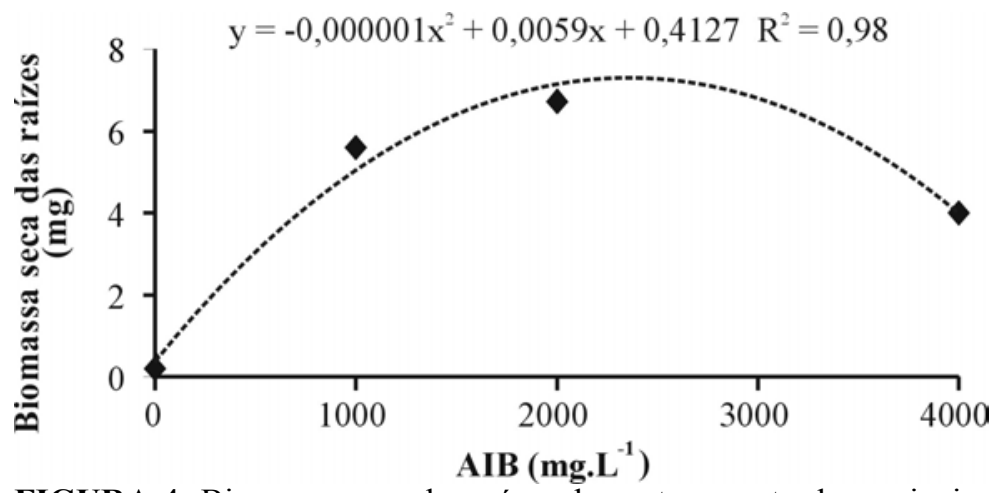

FIGURA 4- Biomassa seca das raízes do porta-enxerto de ameixeira 'Mirabolano'. Lavras-MG, UFLA, 2002.

Para muitas espécies, tem-se observado que o enraizamento só é possível quando as estacas são submersas em reguladores de crescimento, podendo ser benéficos ou inibitórios, dependendo da concentração do mesmo (Rosa, 1993). Alguns trabalhos vêm mostrando os efeitos da aplicação exógena de auxinas em muitas espécies; no entanto, dependendo da concentração, poderá ter efeito inibitório ou fitotóxico (Tofanelli, 1999).

Sharma e Claverie (1989), trabalhando com quatro cultivares de ameixeira, concluíram que os melhores resultados na propagação de estacas, durante o período de verão, foram obtidos utilizando a concentração de $2000 \mathrm{mg} . \mathrm{L}^{-1}$ de AIB. Em experimento realizado por Howard (1985) com a aplicação de AIB na concentração de 2000 mg.L. $\mathrm{L}^{-1}$ em estacas de porta-enxertos clonais de ameixeira, constatou-se que, em todos os clones, houve aumento na porcentagem de estacas enraizadas, maior peso da biomassa fresca, número e diâmetro das raízes.

De acordo com os resultados obtidos neste trabalho e nas 
condições em que o mesmo foi desenvolvido, conclui-se que a vermiculita proporcionou estacas com maior comprimento médio de raízes e maior porcentagem de enraizamento; a concentração de $2000 \mathrm{mg} . \mathrm{L}^{-1}$ de AIB mostrou-se superior para todas as variáveis analisadas.

\section{REFERÊNCIAS BIBLIOGRÁFICAS}

BIASI, L.A. Emprego do estiolamento na propagação de plantas. Ciência Rural, Santa Maria, v.26, n.2, p.309-315, 1996.

BRASIL. Ministério da Agricultura e do Abastecimento. Mapeamento da fruticultura brasileira. Brasília: EMBRAPA-SPI, 2000. 110p.

DUTRA, L.F.; TONIETTO, A.; KERSTEN, E. Efeito da aplicação prévia de ethephon em ameixeira (Prunus salicina Lindl) e do IBA no enraizamento de suas estacas. Scientia Agrícola, Piracicaba, v.55, n.2, p.296-304, maio/ago. 1998.

FACHINELLO, J.C.; HOFFMANN, A.; NACHTIGAL, J.C.; KERSTEN, E.; FONTES, G.R.de L. Propagação de plantas frutíferas de clima temperado. Pelotas: UFEPEL, 1995. 178p.

GOMES, F.P. Curso de estatística experimental. 14. ed. Piracicaba: ESALQ/USP, 2000.477p.

HARTMANN, H.T.; KESTER, D.E.; DAVIES Jr., F.T. Plant propagation: principles and pratices. 6.ed. New Jersey: Prentice Hall, 1997. 770p.

HOFFMANN, A.; CHALFUN, N.N.J.; ANTUNES, L.E.C.; RAMOS, J.D.; PASQUAL, M.; REZENDE e SILVA, C.R. de. Fruticultura comercial: propagação de plantas frutíferas. Lavras: UFLA/FAEPE, 1996.319p.

HOWARD, B.H. Factors affecting the response of leafless winter cuttings of apple and plum to IBA applied in powder formulation. Journal of Horticultural Science, London, v.60, n.2, p.161-168, 1985.

MAYER, N.A. Propagação assexuada do porta-enxerto umezeiro (Prunus mume Sieb \& Zucc.) por estacas herbáceas. 2001. 109f. Dissertação (Mestrado em Produção Vegetal) - Faculdade de Ciências Agrárias e Veterinárias, Universidade Estadual Paulista, Jaboticabal, 2001.

NORBERTO, P.M.; CHALFUN, N.N.J.; PASQUAL, M.; VEIGA, R.D.; PEREIRA, G.E.; MOTA, J.H. Efeito da época de estaquia e do AIB no enraizamento de estacas de figueira (Ficus carica L.). Ciência e Agrotecnologia, Lavras, v.25, n.3, p.533-541, maio/jun. 2001.

OLIVEIRA, J.A. Efeito dos substratos artificiais no enraizamento e no desenvolvimento de maracujazeiro-azedo e doce por estaquia. 2000. 71f. Dissertação (Mestrado em Agronomia) - Universidade de Brasília, Brasília, 2000.

PASQUAL, M.; CHALFUN, N.N.J.; RAMOS, J.D.; VALE, M.R. do; SILVA, REZENDE e SILVA, C.R. de. Fruticultura Comercial: propagação de plantas frutíferas. Lavras: UFLA/FAEPE, 2001. 137p.

PEIXOTO, J.R. Efeito da matéria orgânica, do superfosfato simples e do cloreto de potássio na formação de mudas de maracujazeiro-azedo (Passiflora edulis f. flavicarpa DEN). 1986. 101f. Dissertação (Mestrado em Agronomia) - Universidade Federal de Lavras, Lavras, 1986.

PIO, R. Ácido indolbutírico e sacarose no enraizamento de estacas apicais e desenvolvimento inicial da figueira (Ficus carica L.). 2002. 109p. Dissertação (Mestrado em Agronomia) - Universidade Federal de Lavras, Lavras, 2002.

ROSA, L.S. Influência de diferentes concentrações de ácido indol-3butírico e do tamanho da estaca na formação de raízes adventícias em Carapa guianensis Aubl. In: CONGRESSO FLORESTAL PANAMERICANO, 1., 1993, Curitiba. Anais... Curitiba: SBS-SBEF, v.2, 1993. p.432-434.

SHARMA, S.D.; CLAVERIE, J. Seasonal rooting behavior of cuttings of plum cultivar as influenced by IBA treatments. Scientia Horticulturae, Amsterdan, v.40, p.297-303, 1989.

SILVA, R.P. da; PEIXOTO, J.R.; JUNQUEIRA, N.T.V. Influência de diversos substratos no desenvolvimento de mudas de maracujazeiroazedo (Passiflora edulis Sims f. flavicarpa DEG). Revista Brasileira de Fruticultura, Jaboticabal, v.23, n.2, p.377-381, 2001.

TOFANELLI, M.B.D. Enraizamento de estacas lenhosas e semilenhosas de cultivares de pessegueiro em diferentes concentrações de ácido indolbutírico. 1999. 87p. Dissertação (Mestrado em Agronomia) Universidade Federal de Lavras, Lavras, 1999. 